\title{
UNDERSTANDING AND TAILORING THE MECHANICAL PROPERTIES OF LIGA FABRICATED MATERIALS
}

\author{
T.E BUCHHEIT, T.R. CHRISTENSON, D.T. SCHMALE, AND D.A. LAVAN \\ Sandia National Laboratories, Albuquerque, NM 87185-0333
}

\begin{abstract}
LIGA fabricated materials and components exhibit several processing issues affecting their metallurgical and mechanical properties, potentially limiting their usefulness for MEMS applications. For example, LIGA processing by metal electrodeposition is very sensitive to deposition conditions which causes significant processing lot variations of mechanical and metallurgical properties. Furthermore, the process produces a material with a highly textured lenticular microstructural morphology suggesting an anisotropic material response. Understanding and controlling out-of-plane anisotropy is desirable for LIGA components designed for out-of-plane flexures. Previous work by the current authors [6] focussed on results from a miniature servo-hydraulic mechanical test frame constructed for characterizing LIGA materials. Those results demonstrated microstructural and mechanical properties dependencies with plating bath current density in LIGA fabricated nickel (LIGA Ni). This presentation builds on that work and fosters a methodology for controlling the properties of LIGA fabricated materials through processing. New results include measurement of mechanical properties of LIGA fabricated copper (LIGA Cu), out-ofplane and localized mechanical property measurements using compression testing and nanoindentation of LIGA Ni and LIGA Cu.
\end{abstract}

\section{INTRODUCTION}

The LIGA fabrication process is an additive process in which structural material is typically electrodeposited into a precision mold of plexiglass (PMMA) realized through deep x-ray lithography. $[1,2]$ Representative dimensions of components, which have a prismatic geometry, range from a few micrometers to several millimeters with tolerances of less than 1 micrometer. The components clearly fall within the commonly defined MEMS size regime. Metal electrodepositions such as those carried out in the LIGA process usually generate microstrucutures with fine lenticular grains oriented parallel to the deposition direction. These depositions yield unique mechanical properties that are very sensitive to electrodeposition technique which involves several variables including electroplating bath chemistry, geometry, agitation, and current density. Hence, the variation in mechanical properties that can occur for a given electrodeposited material are dramatic and well-documented. [3,4] A tabletop servohydraulic load frame fitted with a laser displacement measuring system was constructed to evaluate the mechanical properties of LIGA specimens fabricated using different materials under a variety of electroplating conditions. The system has several features that take advantage of the flexible patterning and batch processing associated with LIGA fabrication. [5]

Previous work using the tabletop load frame demonstrated an inverse relationship between material strength and plating bath current density in LIGA Ni. This relationship is directly attributable to the grain size of the fabricated samples which increased with increasing current density. [6] Cross-section micrographs and grain orientation distribution analyses of those LIGA tension specimens revealed other microstructural features which encouraged the current investigation. A typical cross section micrograph of LIGA Ni revealed a very fine grain structure on the intially deposited side of the deposition which gave way to a coarser lenticular grain structure parallel to the electrodeposit growth direction. The lenticular grains remained quite small however, rarely exceeding widths of 2-3 $\mu \mathrm{m}$. Electron Backscatter Imaging (EBSP) on several of the lenticular grains indicated their $\langle 100\rangle$ crystal orientations were always nearly parallel to the growth direction. Two major concerns based on these summarized results are addressed in this paper. First, the presence of a highly textured columnar structure of the LIGA Ni suggests anisotropic mechanical properties in the direction of deposition relative to the plating base plane. Second, local microstructural variations of LIGA Ni, especially near the initially deposited surface, suggest local variations in mechanical properties. Compression tests were performed to ascertain mechanical properties parallel to the growth direction, which are important for components and designs with out-of-plane flexures. Nanoindentation profiling experiments were conducted to characterize the variation in mechanical properties across LIGA Ni samples caused by the change in microstructure from the initially 


\section{DISCLAIMER}

This report was prepared as an account of work sponsored by an agency of the United States Government. Neither the United States Government nor any agency thereof, nor any of their employees, make any warranty, express or implied, or assumes any legal liability or responsibility for the accuracy, completeness, or usefulness of any information, apparatus, product, or process disclosed, or represents that its use would not infringe privately owned rights. Reference herein to any specific commercial product, process, or service by trade name, trademark, manufacturer, or otherwise does not necessarily constitute or imply its endorsement, recommendation, or favoring by the United States Government or any agency thereof. The views and opinions of authors expressed herein do not necessarily state or reflect those of the United States Government or any agency thereof. 


\section{DISCLAIMER}

Portions of this document may be illegible in electronic image products. Images are produced from the best available original document. 
deposited side to the lapped side. Also, new mechanical property results from LIGA deposited copper are presented and discussed, adding to the growing database and understanding of LIGA fabricated materials and components.

\section{EXPERIMENTAL}

\section{Electrodeposition and Sample Preparation}

LIGA Ni electroplating was carried out in a nickel sulfamate bath and LIGA Cu electroplating was carried out in a SEL-REX CUBATH copper sulfate bath which is substantially as purchased from Enthone OMI, Inc. Table I lists the properties of each electroplating bath. Both baths were continuously filtered through a $1.0 \mu \mathrm{m}$ PTFE filter with recirculating agitation. In the case of the LIGA Ni electroplating bath, a low current density treatment was performed onto a corrugated cathode at $1-5 \mathrm{~mA} / \mathrm{cm}^{2}$ for a 72 hour period after bath preparation. Also, the $\mathrm{pH}$ was maintained with sulfamic acid.

\begin{tabular}{|c|c|c|c|}
\hline \multicolumn{2}{|c|}{ Nickel } & \multicolumn{2}{|c|}{ Copper } \\
\hline $\mathrm{Ni}\left(\mathrm{NH}_{2} \mathrm{SO}_{3}\right)_{2} \bullet 4 \mathrm{H}_{2} \mathrm{O}$ & $440.1 \mathrm{~g} / 1$ & $\mathrm{Cu}$ (as metal) & $17 \mathrm{~g} / 1$ \\
\hline Ni (as metal) & $80 \mathrm{~g} / \mathrm{l}$ & Copper sulfate & $68 \mathrm{~g} / 1$ \\
\hline Boric Acid & $48 \mathrm{~g} / 1$ & Sulfuric Acid & $225 \mathrm{~g} / 1$ \\
\hline Wetting Agent & $0.2 \% / \mathrm{vol}$ & CUBATH M-HY & $30 \mathrm{ml} / \mathrm{gal}$ \\
\hline Temperature & $50^{\circ} \mathrm{C}$ & (additive) & \\
\hline $\mathrm{pH}$ & $3.8-4.0$ & Temperature & $25^{\circ} \mathrm{C}$ \\
\hline Anode & sulfur depolarized & $\mathrm{pH}$ & \\
\hline & $\begin{array}{l}\text { nickel in Ti basket } \\
\text { with PTFE bag }\end{array}$ & Anode & $\begin{array}{l}\text { Phosphorized copper } \\
(0.05 \% \text { P) with anode } \\
\text { bag }\end{array}$ \\
\hline
\end{tabular}

Samples for tension and nanoindentation testing were prepared using deep $\mathrm{x}$-ray lithography and electroplating with an unpatterned sacrificial layer. Silicon substrates were prepared with a sputtered $\mathrm{Ti} / \mathrm{Cu}$ plating base at $30 / 100 \mathrm{~nm}$ thickness. Deep x-ray lithography followed with PMMA as the $x$-ray photoresist and electroform mold material. The copper plating base layer seeded the LIGA deposits which were electrodeposited to depths greater than the film thickness, then lapped back flat and parallel to the mold surface. The specimens were released by dissolving the PMMA and selectively etching the underlying copper with an ammonium hydroxide based etchant. The simple cylindrical geometry samples for compression testing were fabricated in the same fashion except the $1 \mathrm{~mm}$ wide by $1.6 \mathrm{~mm}$ high PMMA molds were drilled using a high precision $1 \mathrm{~mm}$ diameter drill bit, instead of fabrication by exposure to $\mathrm{x}$-ray synchrotron radiation.

\section{Mechanical and Microscopic Analyses}

Compression test platens were designed and built for use in the existing table top servohydraulic load frame. Fig. 1 compares a standard tension test with a compression test using the platens. All compression test samples were LIGA Ni fabricated at a current density of $50 \mathrm{~mA} / \mathrm{cm}^{2}$. Specimen dimensions: $1.66 \mathrm{~mm}$ high and $1 \mathrm{~mm}$ in diameter. Metallographic analysis was performed on the compression samples, augmenting the mechanical results.

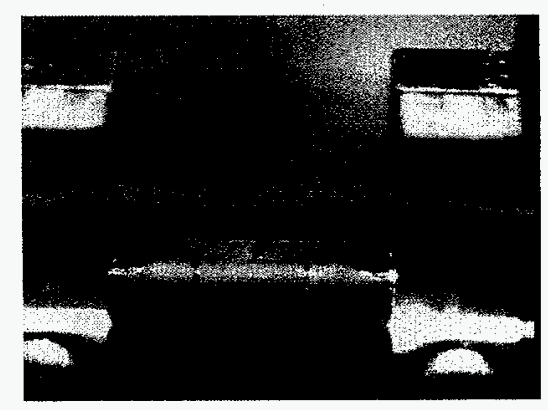

(a)

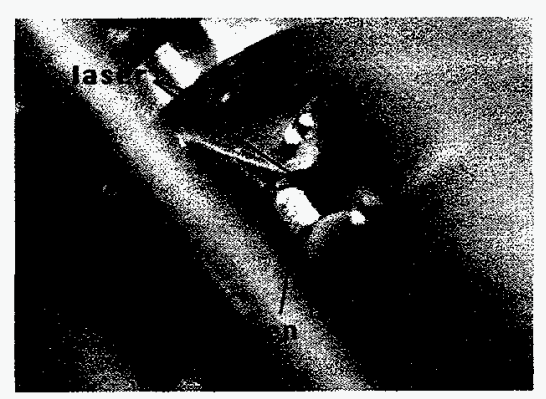

(b)

Fig. 1 (a) Tension test in progress using tabletop mechanical test frame. (b) Compression test using newly designed platens with tabs for measuring displacement 
Nanoindentation profiling was conducted by applying a grid of 3 sided pyramidal Berkovich indents [7] parallel to the initially deposited and lapped sides of cross-sectioned $160 \mu \mathrm{m}$ thick LIGA Ni samples deposited at current densities $20 \mathrm{~mA} / \mathrm{cm}^{2}$ and $50 \mathrm{~mA} / \mathrm{cm}^{2}$, and a LIGA Cu sample deposited at a current density of $30 \mathrm{~mA} / \mathrm{cm}^{2}$. Indentation loads were 2 grams for the LIGA Ni samples and 1 gram for the LIGA Cu sample, indentation spacing within each grid was approximately $15 \mu \mathrm{m} \times 15 \mu \mathrm{m}$. Rows of ten indents parallel to the deposited and lapped surfaces were averaged together to determine the variation of hardness through the thickness of the samples, as suggested by the cross-section metallographic results discussed in the introduction section. An example of this experiment is illustrated in Fig. 2.

Tension testing was conducted on as-desposited and annealed $500^{\circ} \mathrm{C} / 1 \mathrm{hr}$. LIGA Cu samples. The procedure followed that of LIGA $\mathrm{Ni}$ tension testing on the table top servohydraulic mechanical test frame discussed in Ref. [6] and illustrated in Fig. 1.

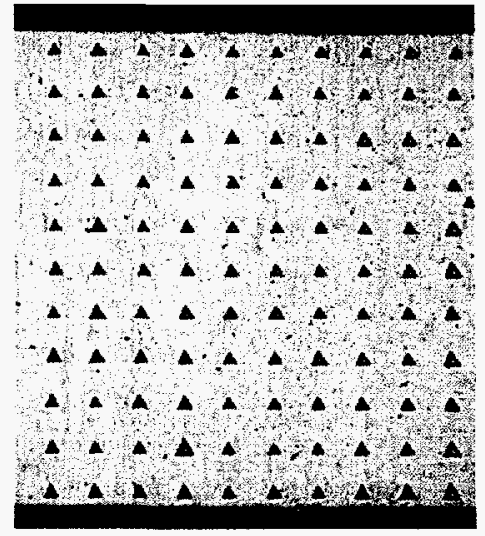

Fig. 2 Nanoindentation profiling on a LIGA Ni cross section plated at a current density of $50 \mathrm{~mA} / \mathrm{cm}^{2}$.

\section{RESULTS}

\section{Compression Testing of LIGA Ni $50 \mathrm{~mA} / \mathrm{cm}^{2}$}

True stress-strain compression test results are plotted and compared with tension test results from LIGA Ni deposited at the same current density, $50 \mathrm{~mA} / \mathrm{cm}^{2}$, in Fig. 3. The compression curves are not compliance corrected. The small difference in $0.2 \%$ proof stress determined from the stress-strain data and also listed in Fig. 3 indicates that the primary difference in stressstrain response of the tension vs. compression tests is caused by compliance in the system during compression testing. Fig. 4 illustrates optical micrographs of cross-sectioned LIGA Ni compression cylinders, the plating direction of the

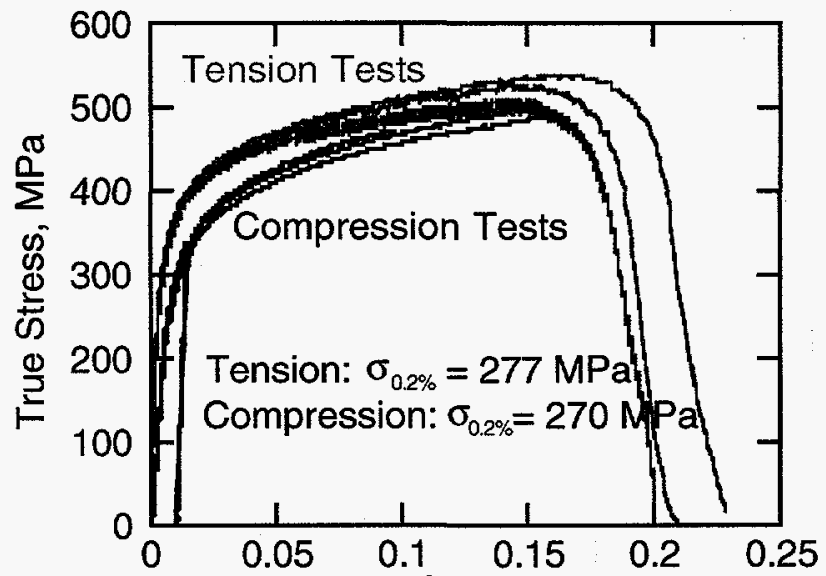

Fig. 3 LIGA Ni $50 \mathrm{~mA} / \mathrm{cm}^{2}$ stress-strain response of in-plane tension samples and compression samples aligned parallel to the plating direction. cylinders is from right to left on the page. These pictures reveal deviations from the expected columnar structure near the plating base side of the compression cylinders. Some PMMA residue remained in the bottom of the mold as a result of drilling the molds rather than removing the PMMA using standard X-ray photolithographic and etching techniques. The change in resistance on the regions of the plating base where PMMA residue was present caused current crowding resulting in a local change in initially deposited microstructure and a deviation from the expected lenticular microstructure favored for determining the mechanical properties in the plating direction. A peculiar change from a generally lenticular microstructure to a more equiaxed structure is observed in the top half of the deformed compression cylinder, illustrated in Fig. 4(b). Also, the high magnification micrograph in Fig. 4(c) revealed small twins in the as plated microstructure.
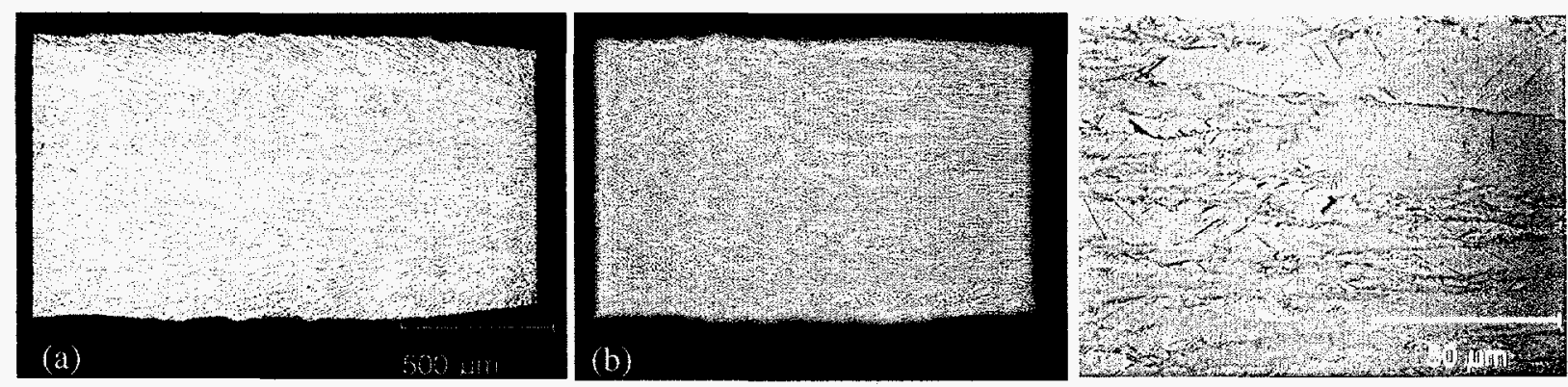

Fig. 4 Cross-section micrographs of (a) undeformed, (b) deformed, and (c) undeformed at high magnification compression test cylinders. 
Table II Mechanical Properties of LIGA Cu

\begin{tabular}{lcccc}
$\begin{array}{l}\text { LIGA Cu } \\
\mathbf{3 0 ~} \mathbf{~ A} / \mathbf{c m}^{2}\end{array}$ & $\begin{array}{c}\mathbf{E} \\
(\mathbf{G P a})\end{array}$ & $\begin{array}{c}\sigma_{\mathbf{0 . 2}} \\
(\mathbf{M P a})\end{array}$ & $\begin{array}{c}\sigma_{\mathrm{f}} \\
(\mathbf{M P a})\end{array}$ & $\varepsilon_{\mathrm{f}}$ \\
\hline \hline As Plated & 101 & 243 & 378 & 0.22 \\
As Plated & 101 & 233 & 370 & 0.22 \\
As Plated & 137 & 240 & 382 & 0.23 \\
$\begin{array}{l}\text { Annealed } \\
\text { 500 }\end{array}$ & 66 & 125 & 325 & 0.27 \\
$\begin{array}{l}\text { Annealed } \\
\text { 500 }\end{array}$ & 86 & 120 & 329 & 0.28
\end{tabular}

Tension Testing of as-deposited and Annealed LIGA Cu

Results from tensile tests on LIGA Cu in the

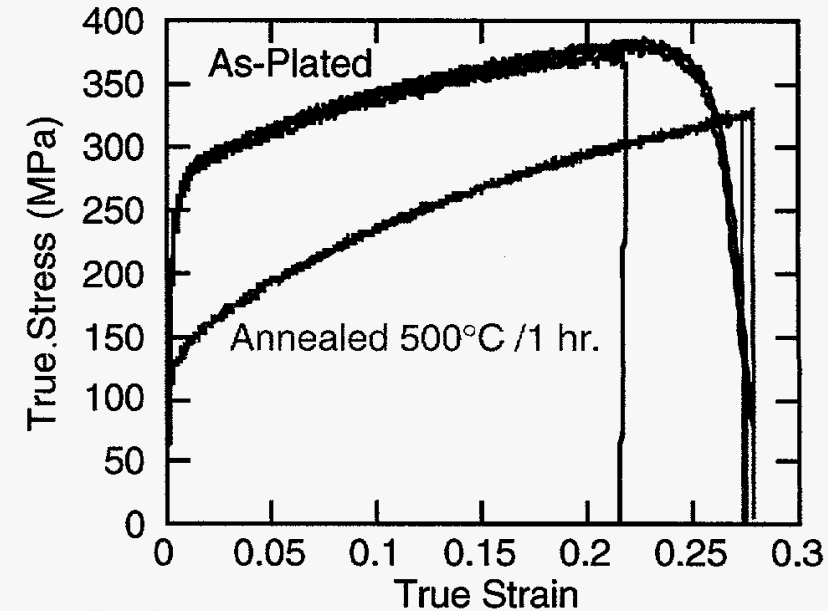

Fig. 5 True stress-strain response of as-deposited and annealed LIGA $\mathrm{Cu}$.

as-deposited and annealed $500^{\circ} \mathrm{C} / 1 \mathrm{hr}$. conditions are illustrated in Fig. 5 and summarized in Table II. The measured elastic modulus for LIGA Cu is about 30\% lower than that measured for LIGA Ni (160 GPa [6]). However, yield strength, fracture stress and fracture strain are somewhat comparable between the two LIGA deposited metals. Both are FCC metals with very similar bulk mechanical properties, except elastic modulus, and differences in measured mechanical response of LIGA deposited Ni and LIGA deposited $\mathrm{Cu}$ can be attributed primarily to differences in grain size and grain orientation texture. Tension tests on annealed LIGA Cu samples revealed an expected reduction in strength due to grain growth during heat treatment. Metallographic cross-sections of as-deposited and annealed LIGA Cu illustrated significant grain growth cause by the heat treatment. Twins were not observed in either LIGA Cu microstructure.

\section{Nanoindentation Profiling of LIGA Ni and LIGA Cu}

Fig. 6 illustrates results from nanoindenation profiling experiments on cross-sections of $160 \mu \mathrm{m}$ thick LIGA Ni deposited at current densities of 50 $\mathrm{mA} / \mathrm{cm}^{2}$ and $20 \mathrm{~mA} / \mathrm{cm}^{2}$, and LIGA Cu. The nanoindentation profiling measurements revealed a trend of increasing hardness near the initially deposited side of the LIGA Ni $50 \mathrm{~mA} / \mathrm{cm}^{2}$ sample. Measured hardness increased $20 \%$ near the deposited surface and increased hardness values extended appproximately $30 \mu \mathrm{m}$ into the sample. Cross section metallography did not clearly indicate the difference between the initially deposited side and the lapped side on the LIGA Ni $20 \mathrm{~mA} / \mathrm{cm}^{2}$ sample. As expected given the smaller grain size in the lower current density sample, average hardness values are significantly higher in the $20 \mathrm{~mA} / \mathrm{cm}^{2}$ sample when compared with the LIGA Ni $50 \mathrm{~mA} / \mathrm{cm}^{2}$. In the LIGA $20 \mathrm{~mA} / \mathrm{cm}^{2}$ sample, nanoindentation profiling did not reveal a significant change in hardness near either surface. Discerning initially deposited and lapped surfaces was not possible using cross-section metallography in the as-deposited LIGA Cu $30 \mathrm{~mA} / \mathrm{cm}^{2}$

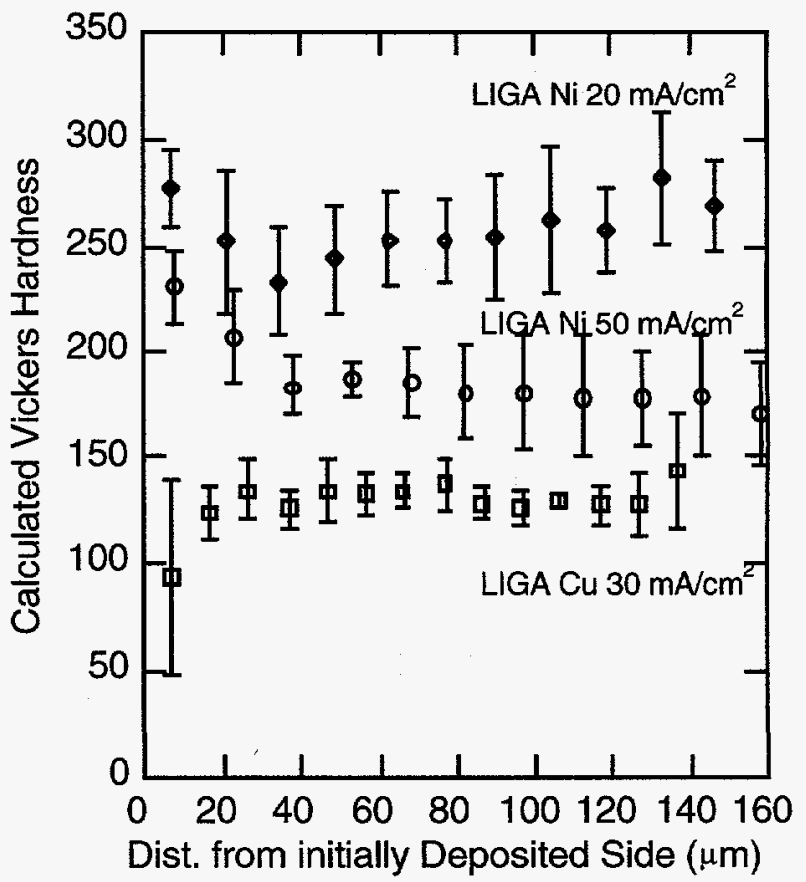

Fig. 6 Results from nanoindentation profile experiments on cross-section LIGA samples. sample. However, cross section nanoindentation profiling on the LIGA Cu sample revealed significant hardness changes near both edges of the sample. Near one edge hardness values measured significantly lower with a very high standard deviation, near the other edge, hardness values increased. Nanoindentation measurements directly on the lapped and initially 
Table II - Summary of Mechanical and Hardness properties on LIGA Cu and LIGA Ni

\begin{tabular}{|c|c|c|c|c|c|c|c|}
\hline & \multicolumn{3}{|c|}{ Mechanical Testing } & \multicolumn{4}{|c|}{ Hardness Testing } \\
\hline Sample & $\begin{array}{c}0.2 \% \text { Proof } \\
\text { Stress (MPa) } \\
\text { Tension } \\
\end{array}$ & $\begin{array}{c}0.2 \% \text { Proof } \\
\text { Stress (MPa) } \\
\text { Compression }\end{array}$ & $\begin{array}{c}\text { Elastic } \\
\text { Modulus } \\
(\mathrm{GPa})\end{array}$ & & $\mathrm{x}$-section & $\begin{array}{l}\text { lapped } \\
\text { side }\end{array}$ & $\begin{array}{c}\text { initially } \\
\text { deposited } \\
\text { side }\end{array}$ \\
\hline \multirow{3}{*}{$\begin{array}{c}\text { LIGA Ni } \\
50 \mathrm{~mA} / \mathrm{cm}^{2} \\
\text { as-deposited }\end{array}$} & \multirow{3}{*}{$\begin{array}{c}277 \pm 7.6 \\
\quad(3)\end{array}$} & \multirow{3}{*}{$\begin{array}{c}270 \pm 1.0 \\
\text { (3) }\end{array}$} & \multirow{3}{*}{$\begin{array}{c}160 \pm 1.0 \\
\text { (3) }\end{array}$} & VHN $100 \mathrm{~g}$ load & $175 \pm 2.4(5)$ & $187 \pm 5.5(10)^{*}$ & $191 \pm 4.5(10)^{*}$ \\
\hline & & & & nano-VHN $2 \mathrm{~g}$ load & $187 \pm 26.2(110)$ & $202 \pm 22.9(20)^{*}$ & $200 \pm 23.6(18)^{*}$ \\
\hline & & & & Elastic Mod. (GPa) & $184 \pm 14.2(110)$ & $146 \pm 10.6(20)^{*}$ & $157 \pm 8.4(20)^{*}$ \\
\hline $\begin{array}{c}\text { LIGA Ni } \\
50 \mathrm{~mA} / \mathrm{cm}^{2} \\
\text { annealed }\end{array}$ & $\begin{array}{c}55 \\
(2) \\
600^{\circ} \mathrm{C} / 1 \mathrm{hr}\end{array}$ & $\begin{array}{c}159 \pm 8.0 \\
(3) \\
550^{\circ} \mathrm{C} / \mathrm{hr} .\end{array}$ & $\begin{array}{l}92 \\
(2)\end{array}$ & & & & \\
\hline \multirow{3}{*}{$\begin{array}{c}\text { LIGA Ni } \\
20 \mathrm{~mA} / \mathrm{cm}^{2} \\
\text { as-deposited }\end{array}$} & \multirow{3}{*}{$\begin{array}{c}441 \pm 27 . \\
\text { (3) }\end{array}$} & & \multirow{3}{*}{$\begin{array}{c}156 \pm 9.3 \\
(3)\end{array}$} & VHN-100g load & $230 \pm 11 .(10)$ & $242+9.1(10)^{*}$ & $257 \pm 3.5(10)^{*}$ \\
\hline & & & & nano-VHN $2 \mathrm{~g}$ load & $258 \pm 28(110)$ & $268 \pm 24(20)^{*}$ & \\
\hline & & & & Elastic Mod. (GPa) & $198 \pm 13(110)$ & $187 \pm 13(20)^{*}$ & \\
\hline \multirow{3}{*}{$\begin{array}{c}\text { LIGA Cu } \\
30 \mathrm{~mA} / \mathrm{cm}^{2} \\
\text { as-deposited }\end{array}$} & \multirow{3}{*}{$\begin{array}{c}239 \pm 5.1 \\
\text { (3) }\end{array}$} & & \multirow{3}{*}{$\begin{array}{c}113 \pm 21 \\
\text { (3) }\end{array}$} & & & & \\
\hline & & & & nano-VHN $1 \mathrm{~g}$ load & $131 \pm 15(138)$ & $123 \pm 4.5(16)$ & $65.4 \pm 10.3(20)$ \\
\hline & & & & Elastic Mod. (GPa) & $133 \pm 12(138)$ & $145 \pm 8.5(20)$ & $113 \pm 11(20)$ \\
\hline LIGA Cu & 122.5 & & 76 & $500^{\circ} \mathrm{C} / 1 \mathrm{hr}$ & & & \\
\hline $30 \mathrm{~mA} / \mathrm{cm}^{2}$ & (2) & & (2) & nano-VHN $1 \mathrm{~g}$ load & $86.4 \pm 10(20)$ & $83.4 \pm 10.4(20)^{*}$ & \\
\hline annealed & $500^{\circ} \mathrm{C} / 1 \mathrm{hr}$ & & & Elastic Mod. (GPa) & $108 \pm 6.7(20)$ & $120.3 \pm 9.1(20)^{*}$ & \\
\hline
\end{tabular}

deposited side of the LIGA Cu sample, given in Table II, indicate that the intially deposited side is signficantly softer than the rest of the deposition.

\section{DISCUSSION}

Table II summarizes mechanical properties data from tension, compression, micro- and nanoindenation tests on LIGA Ni plated at current densities $20 \mathrm{~mA} / \mathrm{cm}^{2}$ and $50 \mathrm{~mA} / \mathrm{cm}^{2}$, and LIGA Cu plated at $30 \mathrm{~mA} / \mathrm{cm}^{2}$. The table includes a few additional experimental results not discussed in the previous section. Some of these experiments were conducted for previous work [6], a few others to complete Table II and assist in discerning key mechanical property trends in LIGA Ni and LIGA Cu. They include tension and compression tests on annealed LIGA Ni, and small scale hardness testing on the deposited and lapped sides of LIGA Ni $20 \mathrm{~mA} / \mathrm{cm}^{2}$, LIGA Ni $50 \mathrm{~mA} / \mathrm{cm}^{2}$ and LIGA Cu $30 \mathrm{~mA} / \mathrm{cm}^{2}$. In Table II, numbers inside parenthesis indicate the number of tests taken for each averaged value listed and asterisks denote hardness testing was conducted on samples with metallographically polished surfaces.

The LIGA Ni $50 \mathrm{~mA} / \mathrm{cm}^{2}$ annealed tension and compression data is compared in the second row of Table II. Although the tension tests were conducted in a different orientation relative to the compression tests, the mechanical strength of the material in the as-deposited condition is very nearly the same, as noted in the previous section. Consequently, the significant difference in strength of the annealed LIGA Ni in tension vs. compression listed in the same row is caused by the relatively small difference in annealing temperatures, $600^{\circ} \mathrm{C}$ vs. $550^{\circ} \mathrm{C}$. This result suggests that the choice of temperatures, within $50^{\circ} \mathrm{C}$, for high temperature $\left(300^{\circ} \mathrm{C}-900^{\circ} \mathrm{C}\right)$ processing operations on LIGA Ni, such as diffusion bonding, imparts significant changes in mechanical properties. An annealing temperature vs. mechanical properties study to determine heat treatment temperatures would optimize such processing operations.

Table II indicates a large change in elastic modulus measured in tension between the as-deposited and annealed LIGA Ni and LIGA Cu. In each case, the measured elastic modulus of the annealed material is very low, yet elastic modulus measurements [7] taken during the unloading step of nanoindentation tests on LIGA Cu give elastic modulus values much more consistent with as-deposited LIGA Cu. The low elastic modulus measurements in tension of the annealed materials could be caused by a combination of 
the somewhat diffuse yielding behavior ubiquitous in pure annealed FCC metals and displacement measurement resolution not fine enough to accurately observe this at low strains on small specimens. Nevertheless, all stress-stress curves of annealed LIGA Ni and LIGA Cu (some are illustrated in [6]) exhibited distinctive knee-bend transitions from elastic to plastic deformation, providing evidence that the "diffuse yield" explanation is not a valid one. Reduced constraint due to few grains through the thickness in the gage length of the tension specimens or grain orientation anisotropy are other possible explanations for the unusually low measured modulus value of the annealed materials in Table II. However, in the case of annealed LIGA Ni, the elastic modulus measured in tension is less than the theoretical lower limit of elastic modulus in a nickel single crystal, $137 \mathrm{GPa}$.

A comparison of hardness and modulus values on the right hand side of Table II reveals the apparent anisotropy and variability of mechanical properties in LIGA deposited samples. In all cases of micro- and nano- hardness testing, hardness and modulus values differ significantly between cross-sections and polished top and bottom sides of LIGA deposited samples. The nanohardness tests on LIGA Cu deposited at $30 \mathrm{~mA} / \mathrm{cm}^{2}$ are the only set of hardness measurements where the top and bottom, or lapped and initially deposited, sides were not polished thus no affected near surface layers were removed and more representative surface hardness measurements were taken. In this case, a very large difference, 123 VHN vs. 65 VHN, in hardness was observed between the lapped and initially deposited surfaces. These results permitted determination of the initially deposited and lapped sides of the LIGA Cu sample data presented in Fig 6. LIGA Cu exhibits softening near the initially deposited surface and hardening near the lapped surface, a very different observation from the LIGA deposited Ni samples.

In summary, using the fabrication methods discussed in this paper, a LIGA Ni or LIGA Cu component will exhibit a different surface hardness on each surface of the component, in LIGA Cu this difference is very large. The same component will most likely exhibit a variation in mechanical properties through the thickness of the deposition. In LIGA Ni, this variation was exhibited up to $40 \mu \mathrm{m}$ deep on the initially deposited side of a sample. In LIGA $\mathrm{Cu}$, this variation was exhibited on both sides of the sample, albeit not nearly as deep. An anisotropic mechanical response which varies out of the deposition plane is expected but not yet observed as a result of the highly $\langle 100\rangle$ oriented lenticular grain structure in the LIGA Ni depositions. The grain orientation distribution and microstructural morphology are currently not as well characterized in LIGA Cu, thus no qualitative determination of this materials' out-of plane mechanical response can be made at this time. Finally, both materials exhibit rapid softening due to grain growth at modest to high annealing temperatures but evidence suggests that quantification of mechanical properties vs. heat treatment temperatures would optimize high temperature post processing operations on LIGA fabricated materials.

\section{ACKNOWLEDGEMENTS}

The authors gratefully acknowledge Alice Kilgo from Dept. 1822 at SNL for performing the metallographic analyses presented in this paper. Sandia is a multiprogram laboratory operated by Sandia Corporation, a Lockheed Martin Company, for the United States Department of Energy under contract DEAC04-94AL8500.

\section{REFERENCES}

1. E.W. Becker, W. Ehrfled, P. Hagmann, A Maner, and D. Munchmeyer, Microelectronic Eng., 4, pp 35-56 (1986).

2. T.R. Christenson and H. Guckel in Micromahcing in and Microfabrication Process Technology (SPIE Proceedings, 2639, Austin, Tx, 1995) pp. 134-145.

3. M.L. Whitehurst in Symposium on Electrodeposited Metals as Materials for Selected Applications (MCIC-7205 report for Metals and Ceramics Information Center, Airforce Materials Laboratory, 1972), pp. 53-64.

4. W. H. Safranek, The Properties of Electrodeposited Metals and Alloys, (American Electroplaters and Surface finishers Society, Orlando Fl, 1986.

5. D.T. Schmale, R.J. Bourcier and T.E. Buchheit, Description of a Micromechanical Testing System, SAND971608 (Sandia National Laboratories, Albuquerque, NM, 1997)

6. T.R. Christenson, T.E. Buchheit, D.T. Schmale and R.J. Bourcier in Microelectromechanical Structures for Materials Research (Mater. Res. Soc. Proc.) to be published.

7. W.C. Oliver and G.M. Pharr, J. Mater. Res., 7, pp. 1564-1583, (1992). 